\title{
A case of tamoxifen-induced hypertriglyceridemia monitoring the changes in lipoprotein fractions over time
}

\author{
Hayato Isobe ${ }^{1}$, Masashi Shimoda ${ }^{1 *} \mathbb{D}$, Yuki Kan', Fuminori Tatsumi', Yukino Katakura', Tomohiko Kimura', \\ Atsushi Obata', Kenji Kohara', Shuhei Nakanishi', Tomoatsu Mune' ${ }^{1}$,Kohei Kaku² and Hideaki Kaneto ${ }^{1}$
}

\begin{abstract}
Background: Tamoxifen, which is one of the selective estrogen receptor modulators (SERMs), can bring out lifethreatening complication, e.g. hypertriglyceridemia-induced acute pancreatitis, although it is rare. We precisely report changes in lipoprotein metabolism before and after tamoxifen discontinuation because there have been few reports of it.

Case presentation: 47-year-old premenopausal woman with dyslipidemia, type 2 diabetes, nonalcoholic fatty liver disease and chronic kidney disease was prescribed tamoxifen as adjuvant therapy after operation of breast cancer. She experienced severe tamoxifen-induced hypertriglyceridemia several months after dosing tamoxifen. Before cessation of tamoxifen, lipoprotein fraction test revealed marked stagnation of VLDL and IDL metabolisms, resulting in severe hypertriglyceridemia (serum triglyceride level was $1881 \mathrm{mg} / \mathrm{dL}$ ). Seven days after tamoxifen withdrawal, lipoprotein fraction test showed that the metabolisms of endogenous lipoproteins were changed drastically.

Conclusions: From these results, we confirmed that tamoxifen certainly changes lipoprotein metabolism through suppression of post-heparin lipolytic activity. It is very important to evaluate the balance between benefit and risk before dosing tamoxifen and survey lipid profiles constantly during treatment to avoid life-threatening complication when prescription of tamoxifen is planned.
\end{abstract}

Keywords: Tamoxifen, Hypertriglyceridemia, Lipoprotein fraction, Type 2 diabetes

\section{Background}

Tamoxifen is one of the selective estrogen receptor modulators (SERMs) widely prescribed as adjuvant therapy for breast cancer which is estrogen receptor positive, progesterone receptor positive, or both [1]. Approximately $70 \%$ of breast cancers are estrogen receptor positive [2]. Tamoxifen interferes with the estrogendependent proliferation of breast cancer cells [3] and reduces mortality and recurrence rate [4-6]. Although the adverse effects of tamoxifen are generally recognized to

\footnotetext{
* Correspondence: masashi-s@med.kawasaki-m.ac.jp

'Division of Diabetes, Metabolism and Endocrinology, Kawasaki Medical School, 577 Matsushima, Kurashiki 701-0192, Japan

Full list of author information is available at the end of the article
}

be mild, its use is associated with significantly increased risks of endometrial cancer, gastrointestinal cancers, strokes and pulmonary emboli [7]. In contrast, tamoxifen significantly decreased myocardial infarction deaths and was associated with a statistically insignificant decrease in myocardial infarction incidence [7]. Although several studies described small changes in plasma lipoprotein concentrations, most of the changes reduced the risk of cardiovascular disease [8-10]. On the other hand, tamoxifen can bring out life-threatening complication, e.g. hypertriglyceridemia-induced acute pancreatitis, although it is rare [11]. Therefore, consideration about the balance of potential benefits and risks is required when using tamoxifen for long term. 
We experienced a case with marked hypertriglyceridemia after tamoxifen administration. In this case report, we precisely report the change of lipoprotein fractions and each apolipoprotein level before and after withdrawal of tamoxifen.

\section{Case presentation}

A case is 47-year-old premenopausal woman with dyslipidemia, type 2 diabetes, nonalcoholic fatty liver disease and chronic kidney disease. In March 2016, she was diagnosed with diabetes and dyslipidemia in preoperative examination of uterine myoma at hospital of referral source. When she was referred to our hospital, she had significant disorder of glucose and lipid metabolism. The data of her blood test were as below; HbA1c 14.2\%, plasma glucose $364 \mathrm{mg} / \mathrm{dL}$, total cholesterol (TC) 315 $\mathrm{mg} / \mathrm{dL}$, triglyceride (TG) $698 \mathrm{mg} / \mathrm{dL}$, LDL-cholesterol (LDL-C) $147 \mathrm{mg} / \mathrm{dL}$ and non HDL-cholesterol (non HDL-C) $261 \mathrm{mg} / \mathrm{dL}$. We immediately started treatment for dyslipidemia with $2.5 \mathrm{mg}$ of rosuvastatin, in addition to treatment for diabetes. In June of the same year, she was also prescribed $80 \mathrm{mg}$ of fenofibrate to treat hypertriglyceridemia with fasting TG $579 \mathrm{mg} / \mathrm{dL}$. Although levels of HbA1c and TG were improved to $6.4 \%$ and $247 \mathrm{mg} / \mathrm{dL}$, respectively, fenofibrate was stopped because her renal function deteriorated to eGFR $43.3 \mathrm{ml} /$ $\mathrm{min} / 1.75 \mathrm{~m}^{2}$ in September 2017. In March 2018, she was prescribed $400 \mathrm{mg}$ of tocopherol nicotinate because the TG value was re-increased to $418 \mathrm{mg} / \mathrm{dL}$, and TG level was continued in $200-300 \mathrm{mg} / \mathrm{dL}$ after dosing it. She was diagnosed as breast cancer in April of the same year and had the breast cancer operation in May and was prescribed $400 \mathrm{mg}$ of tamoxifen as adjuvant therapy in August. In September of the same year, rosuvastatin was withdrawn by transient exacerbation of renal function due to dehydration. After then, serum TG concentration was continued in $200-270 \mathrm{mg} / \mathrm{dL}$ to December of the same year, but it was gradually worsened to $387 \mathrm{mg} / \mathrm{dL}$ in January and to $539 \mathrm{mg} / \mathrm{dL}$ in March 2019. She was hospitalized for treatment of hypertriglyceridemia in September 2019 because of the deterioration of TG level to $1881 \mathrm{mg} / \mathrm{dL}$ with asymptomatic increment of serum pancreatic amylase.

On admission, physical examination showed no goiter, no Cushing signs (e.g. central obesity, red striae cutis and buffalo hump etc.) and no obesity (BMI $22.6 \mathrm{~kg} / \mathrm{m}^{2}$ ). No cutaneous and retinal signs of primary hypertriglyceridemia were detected. She had no alcohol abuse, but had an unbalanced diet with carbohydrates and no exercise habits. She also had no history of cardiovascular disease and acute pancreatitis. Although she had no family history of dyslipidemia or cardiovascular disease within the interview survey, we could not completely rule out hereditary disorders, such as familial combined hyperlipidemia, because we could not perform further investigation due to the patient's special family situation. She was also prescribed $0.5 \mathrm{mg}$ of glimepiride once daily and $0.75 \mathrm{mg}$ of dulaglutide once weekly for type 2 diabetes, $400 \mathrm{mg}$ of tocopherol nicotinate twice daily for dyslipidemia, $20 \mathrm{mg}$ of tamoxifen as adjuvant therapy for breast cancer before admission.

She underwent fasting blood draws throughout the clinical course. The results in fasting blood sampling in the next morning of the admission were shown in Tables 12 and 3 and Fig. 1. As shown in Table 1 and Fig. 1, lipoprotein fraction test by using high performance liquid chromatography (HPLC) method indicated an increase of VLDL fraction mainly, and no chylomicron fraction. Serum standing test was also negative (data not shown), showing no presence of chylomicrons. This VLDL metabolic disorder was considered to be a factor in the marked increase of TG concentration.

Table 1 Lipid parameters in fasting blood sampling in the next morning of admission

\begin{tabular}{|c|c|c|c|}
\hline Clinical parameters & Results & Units & Standard value \\
\hline \multicolumn{4}{|c|}{ Parameters related with lipid metabolism } \\
\hline $\mathrm{TC}$ & 347 & $\mathrm{mg} / \mathrm{dL}$ & $142-248$ \\
\hline TG & 964 & $\mathrm{mg} / \mathrm{dL}$ & $30-149$ \\
\hline $\mathrm{HDL}-\mathrm{C}$ & 34 & $\mathrm{mg} / \mathrm{dL}$ & $40-103$ \\
\hline LDL-C & 68 & $\mathrm{mg} / \mathrm{dL}$ & $65-139$ \\
\hline non $\mathrm{HDL}-\mathrm{C}$ & 313 & $\mathrm{mg} / \mathrm{dL}$ & $95-169$ \\
\hline RLP-C & 59.0 & $\mathrm{mg} / \mathrm{dL}$ & $0.0-7.5$ \\
\hline Prehepalin LPL mass & 94 & $\mathrm{ng} / \mathrm{mL}$ & \\
\hline Apo A-I & 148 & $\mathrm{mg} / \mathrm{dL}$ & $126-165$ \\
\hline Apo B & 158 & $\mathrm{mg} / \mathrm{dL}$ & $66-101$ \\
\hline Apo C-II & 21.8 & $\mathrm{mg} / \mathrm{dL}$ & $1.5-3.8$ \\
\hline Apo C-III & 63.4 & $\mathrm{mg} / \mathrm{dL}$ & $5.4-9.0$ \\
\hline Apo E & 14.7 & $\mathrm{mg} / \mathrm{dL}$ & $2.8-4.6$ \\
\hline \multicolumn{4}{|c|}{ Lipoprotein fraction test (HPLC method) } \\
\hline $\mathrm{HDL}$ & 9.7 & $\%$ & $23.6-49.8$ \\
\hline LDL & 19.6 & $\%$ & $42.2-63.8$ \\
\hline IDL & 9.6 & $\%$ & $2.2-6.1$ \\
\hline VLDL & 59.6 & $\%$ & $2.6-13.9$ \\
\hline Other & 1.6 & $\%$ & $0.8-4.4$ \\
\hline HDL (quantity) & 33.6 & $\mathrm{mg} / \mathrm{dL}$ & $40.6-91.4$ \\
\hline LDL (quantity) & 67.9 & $\mathrm{mg} / \mathrm{dL}$ & $67.8-132.6$ \\
\hline IDL (quantity) & 33.4 & $\mathrm{mg} / \mathrm{dL}$ & $3.8-12.5$ \\
\hline VLDL (quantity) & 206.8 & $\mathrm{mg} / \mathrm{dL}$ & $4.9-22.8$ \\
\hline Other (quantity) & 5.4 & $\mathrm{mg} / \mathrm{dL}$ & $1.5-9.1$ \\
\hline Total cholesterol (quantity) & 347 & $\mathrm{mg} / \mathrm{dL}$ & $150-219$ \\
\hline
\end{tabular}

TC total cholesterol, TG triglyceride, HDL-C high density lipoproteincholesterol, LDL-C low density lipoprotein- cholesterol, RLP-C remnant lipoprotein- cholesterol, LPL lipoprotein lipase, Apo apolipoprotein, HPLC High Performance Liquid Chromatography 
Table 2 Other parameters in fasting blood sampling in the next morning of admission

\begin{tabular}{|c|c|c|c|}
\hline Clinical parameters & Results & Units & Standard value \\
\hline \multicolumn{4}{|c|}{ Parameters related with glucose metabolism } \\
\hline $\mathrm{HbA1c}$ & 7.3 & $\%$ & $4.9-6.0$ \\
\hline Plasma glucose & 162 & $\mathrm{mg} / \mathrm{dL}$ & 73-109 \\
\hline \multicolumn{4}{|c|}{$\begin{array}{l}\text { Parameters related with hepatic damage, renal function and pancreatic } \\
\text { exocrine enzyme }\end{array}$} \\
\hline T-Bil & 0.8 & $\mathrm{mg} / \mathrm{dL}$ & $0.4-1.5$ \\
\hline үGTP & 37 & $U / L$ & $9-32$ \\
\hline ALT & 15 & $U / L$ & $7-23$ \\
\hline AST & 15 & $U / L$ & $13-30$ \\
\hline Cre & 1.40 & $\mathrm{mg} / \mathrm{dL}$ & $0.46-0.79$ \\
\hline eGFR & 32.9 & $\mathrm{ml} / \mathrm{min} / 1.73 \mathrm{~m}^{2}$ & $\geq 60$ \\
\hline P-Amy & 72 & $U / L$ & $18-53$ \\
\hline Elastase 1 & 314 & $\mathrm{ng} / \mathrm{mL}$ & $0-300$ \\
\hline Lipase & 410 & $U / L$ & 73-393 \\
\hline \multicolumn{4}{|c|}{ Urine qualitative analysis } \\
\hline Uric protein & $1+$ & & - \\
\hline Uric glucose & - & & - \\
\hline Uric ketone & - & & - \\
\hline \multicolumn{4}{|l|}{ Other parameters } \\
\hline FT4 & 1.23 & $\mathrm{ng} / \mathrm{mL}$ & $0.68-1.26$ \\
\hline TSH & 1.32 & $\mu \mathrm{UU} / \mathrm{mL}$ & $0.75-4.12$ \\
\hline Cortisol & 22.6 & $\mu g / d L$ & $4.5-21.1$ \\
\hline $\mathrm{ACTH}$ & 22.6 & $\mathrm{pg} / \mathrm{mL}$ & $7.2-63.3$ \\
\hline DHEA-S & 170 & $\mu \mathrm{g} / \mathrm{dL}$ & $19-231$ \\
\hline
\end{tabular}

$T$-Bil total bilirubin, $\gamma G T P \gamma$-glutamyl transpeptidase, $A L T$ alanine aminotransferase, AST aspartate aminotransferase, Cre creatinine, eGFR estimated glomerular filtration rate, $P$-Amy pancreatic amylase, $F T$; free thyroxine, TSH thyroid-stimulating hormone, $A C T H$ adrenocorticotropic hormone, DHEA-S dehydroepiandrosterone sulfate

Remnant lipoprotein (RLP)-C and non HDL-C were also significantly augmented (Table 1). The degree of increase of apolipoprotein CIII level was higher than that of apolipoprotein CII level (Table 1), Furthermore, lipoprotein fraction test by using polyacrylamide gel electrophoresis (PAGE) method revealed the fraction which was named "BAND 1" with the smaller particle size than LDL, implying the existence of small dense LDL (Fig. 1b and Table 3). We also confirmed the existence of small dense LDL by calculating LDL-migration index (LDL$\mathrm{MI}$ ) and LDL-C/Apo B ratio (Table 3), the indicators of small dense LDL [12]. Furthermore, HbA1c level was $7.3 \%$, and the image of abdominal computed tomography on admission revealed the presence of fatty liver because the hepatic parenchymal density fell in patchy fashion (Fig. 2), although the index of hepatic damage, such as ALT, AST, yGTP, was not increased (Table 2). Marked hypertriglyceridemia was thought to be due to multiple factors such as unbalanced diet, no exercise habit, uncontrolled diabetes, fatty liver, chronic kidney disease and tamoxifen therapy. On the other hand, there was little change in the clinical course before hospitalization of factors, such as eGFR, body weight (Fig. 3) and HbA1c, other than tamoxifen therapy. Therefore, we speculated that the main factor of rapid exacerbation of TG value was tamoxifen therapy.

Before hospitalization, asymptotic increase of serum pancreatic amylase, elastase 1 and lipase was observed (Table 2). Although we considered hypertriglyceridemiainduced acute pancreatitis, we could not confirm any findings that positively suggested the onset of pancreatitis in abdominal computed tomography. Since the increase in exocrine pancreatic enzymes was relieved with the improvement of renal function, it was considered to be pseudo-hyperamylasemia (Table 3). Therefore, we did not instruct fasting during hospitalization.

After discontinuation of tamoxifen therapy, there were no conspicuous changes in the percentage of each fractions in lipoprotein fraction test by PAGE method seven days after tamoxifen withdrawal (Table 3), but the wave profile of each fractions changed prominently (Fig. 4a). These changes revealed that withdrawal of tamoxifen contributed to improvement of TG-rich lipoprotein metabolism, resulting in decrease of TG level. Furthermore, we prescribed pemafibrate, which is expected to have little effect on renal function, because improvement in renal function was confirmed after admission. After prescribing pemafibrate, the parameters, such as TG, non HDL-C and RLP-C, related with TG-rich lipoprotein metabolism were improved (Table 3 ), but LDL-C was increased (Table 3 and Fig. 4b). On the other hand, lipoprotein fraction test by PAGE method revealed the loss of small dense LDL fraction (Fig. 4b). LDL-MI and LDL$\mathrm{C} / \mathrm{Apo} \mathrm{B}$ ratio were also changed from 0.67 to $0.37,0.51$ to 1.10 , respectively (Table 3 ).

\section{Discussion and conclusions}

We experienced an acute exacerbation of hypertriglyceridemia after tamoxifen administration in patient who had already suffered from hypertriglyceridemia due to chronic kidney disease (CKD), diabetes, nonalcoholic fatty liver disease (NAFLD).

unbalanced diet with carbohydrates and no exercise habit. Some authors have reported that severe hypertriglyceridemia by tamoxifen therapy usually occurs in those patients who have a previous diagnosis of familial hypertriglyceridemia or familial combined hyperlipidemia, and that in normolipidemic patients there is only moderate elevation of triglycerides [13]. Although she had no family history of dyslipidemia or cardiovascular disease within the interview survey, we could not completely rule out hereditary disorders, such as familial combined hyperlipidemia, because we could not perform 
Table 3 Change of clinical parameters after admission

\begin{tabular}{|c|c|c|c|c|}
\hline \multirow[t]{2}{*}{ Parameters } & \multirow[t]{2}{*}{ Units } & \multicolumn{2}{|l|}{ In hospital } & \multirow{2}{*}{$\begin{array}{l}\text { After discharge } \\
2 \text { months after dosing pemafibrate }\end{array}$} \\
\hline & & Under dosing tamoxifen & 7 days after tamoxifen withdrawal & \\
\hline \multicolumn{5}{|c|}{ Parameters related with lipid metabolism } \\
\hline TC & $\mathrm{mg} / \mathrm{dL}$ & 341 & 282 & 234 \\
\hline TG & $\mathrm{mg} / \mathrm{dL}$ & 964 & 675 & 231 \\
\hline $\mathrm{HDL}-\mathrm{C}$ & $\mathrm{mg} / \mathrm{dL}$ & 34 & 33 & 46 \\
\hline LDL-C & $\mathrm{mg} / \mathrm{dL}$ & 68 & 114 & 156 \\
\hline non-HDL-C & $\mathrm{mg} / \mathrm{dL}$ & 307 & 249 & 188 \\
\hline RLP-C & $\mathrm{mg} / \mathrm{dL}$ & 59.0 & - & 11.3 \\
\hline Apo A-I & $\mathrm{mg} / \mathrm{dL}$ & 148 & & 153 \\
\hline Apo B & $\mathrm{mg} / \mathrm{dL}$ & 158 & 155 & 142 \\
\hline Apo C-II & $\mathrm{mg} / \mathrm{dL}$ & 21.8 & 14.5 & 9.5 \\
\hline Apo C-III & $\mathrm{mg} / \mathrm{dL}$ & 63.4 & 33.9 & 20.0 \\
\hline Apo C-III/C-II ratio & & 2.9 & 2.3 & 2.1 \\
\hline Apo E & $\mathrm{mg} / \mathrm{dL}$ & 14.7 & & 5.5 \\
\hline LDL-C/ Apo B ratio & & 0.51 & 0.73 & 1.10 \\
\hline \multicolumn{5}{|c|}{ Lipoprotein fraction test (PAGE method) } \\
\hline $\mathrm{HDL}$ & $\%$ & 18 & 10 & 17 \\
\hline BAND 1 & $\%$ & 4 & 16 & \\
\hline LDL & $\%$ & 16 & 12 & 44 \\
\hline MIDBAND & $\%$ & 39 & 35 & 24 \\
\hline VLDL & $\%$ & 23 & 27 & 15 \\
\hline LDL-MI & & 0.67 & 0.60 & 0.37 \\
\hline \multicolumn{5}{|l|}{ Other parameters } \\
\hline $\mathrm{HbA1c}$ & $\%$ & 7.3 & - & 7.0 \\
\hline Cre & $\mathrm{mg} / \mathrm{dL}$ & 1.40 & & 1.00 \\
\hline eGFR & $\mathrm{ml} / \mathrm{min} / 1.75 \mathrm{~m}^{2}$ & 32.9 & & 47.5 \\
\hline P-Amy & $U / L$ & 72 & 53 & - \\
\hline
\end{tabular}

(a)

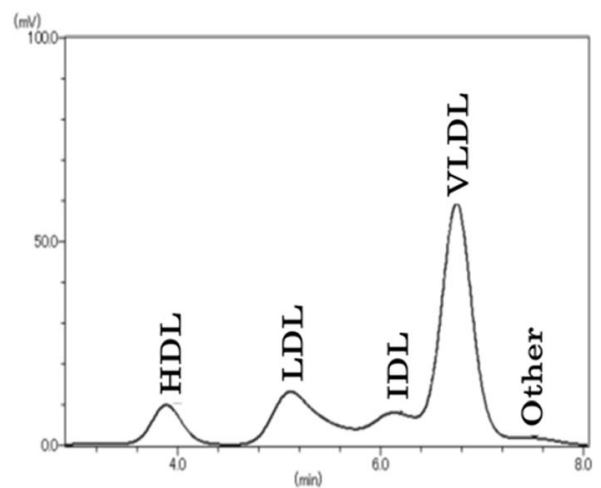

(b)

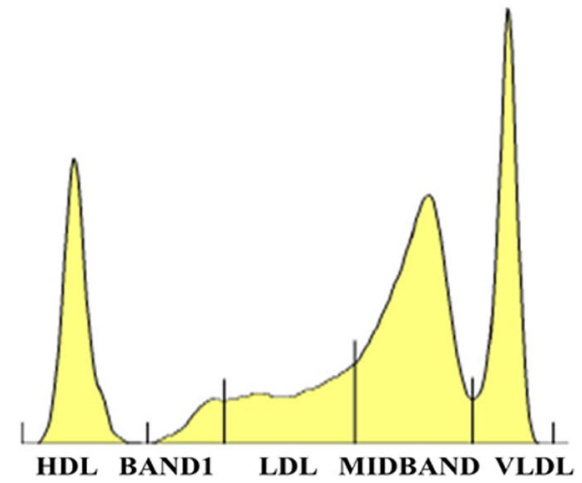

Fig. 1 The results of lipoprotein fraction test in the next morning of admission. a Lipoprotein fraction test by using high performance liquid chromatography (HPLC) method and $\mathbf{b}$ polyacrylamide gel electrophoresis (PAGE) method in the next morning of admission 


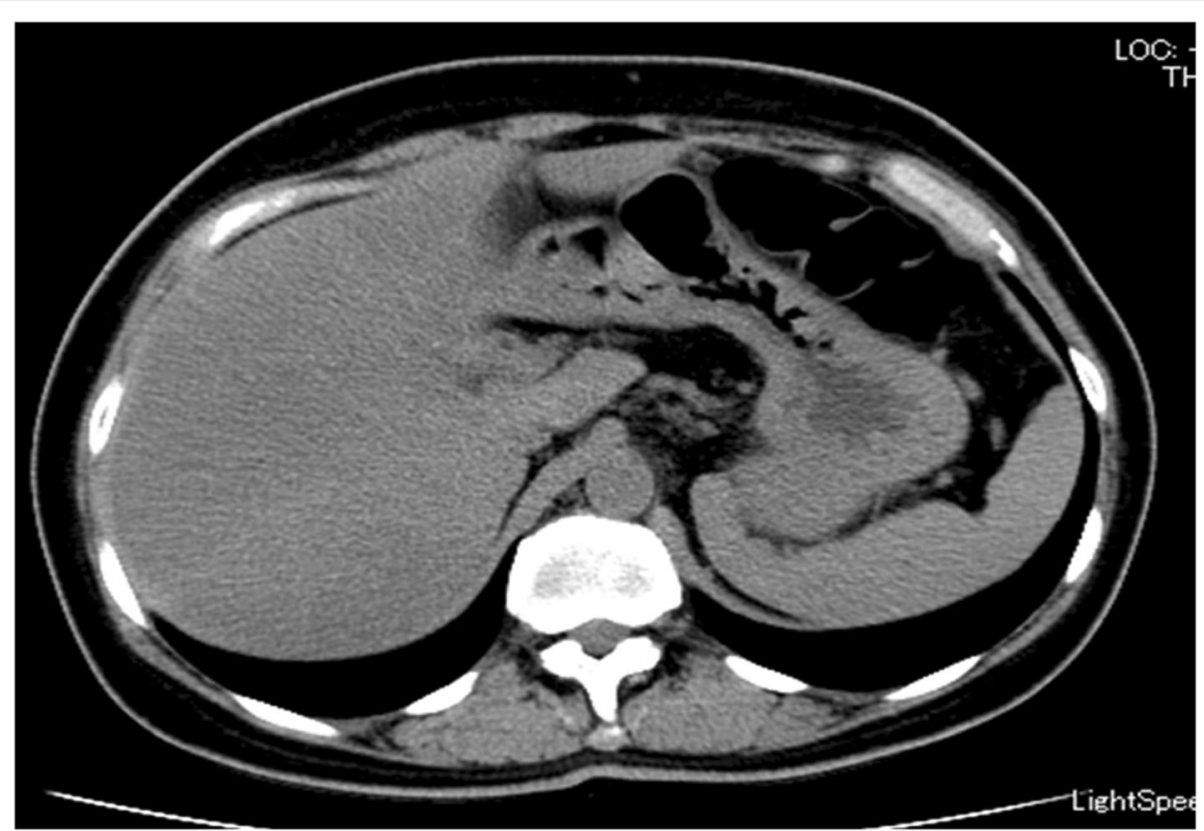

Fig. 2 Abdominal computed tomography on admission. The image reveals the presence of fatty liver because the hepatic parenchymal density falls in patchy fashion

further investigation due to the patient's special family situation. The possible presence of hereditary dyslipidemia remains a factor in the marked exacerbation of hypertriglyceridemia with tamoxifen treatment. In this case, the onset of hypertriglyceridemia-induced acute pancreatitis due to tamoxifen therapy was not confirmed, but previous reports have revealed that tamoxifen increases serum triglyceride level and triggers hypertriglyceridemia-induced acute pancreatitis, whereas its incidence is rare [11]. Marked hypertriglyceridemia is an uncommon but well-established etiology of acute pancreatitis, with a reported incidence of 2-4\% [14-16]. Data from European population studies reported that incidence of acute pancreatitis was $10-19 \%$ in subjects with severe hypertriglyceridemia, e.g. TG level is $\geq 1000$ $\mathrm{mg} / \mathrm{dL}$ [16]. Several studies have revealed that hypertriglyceridemia-induced acute pancreatitis is more likely to follow more severe clinical course, e.g.

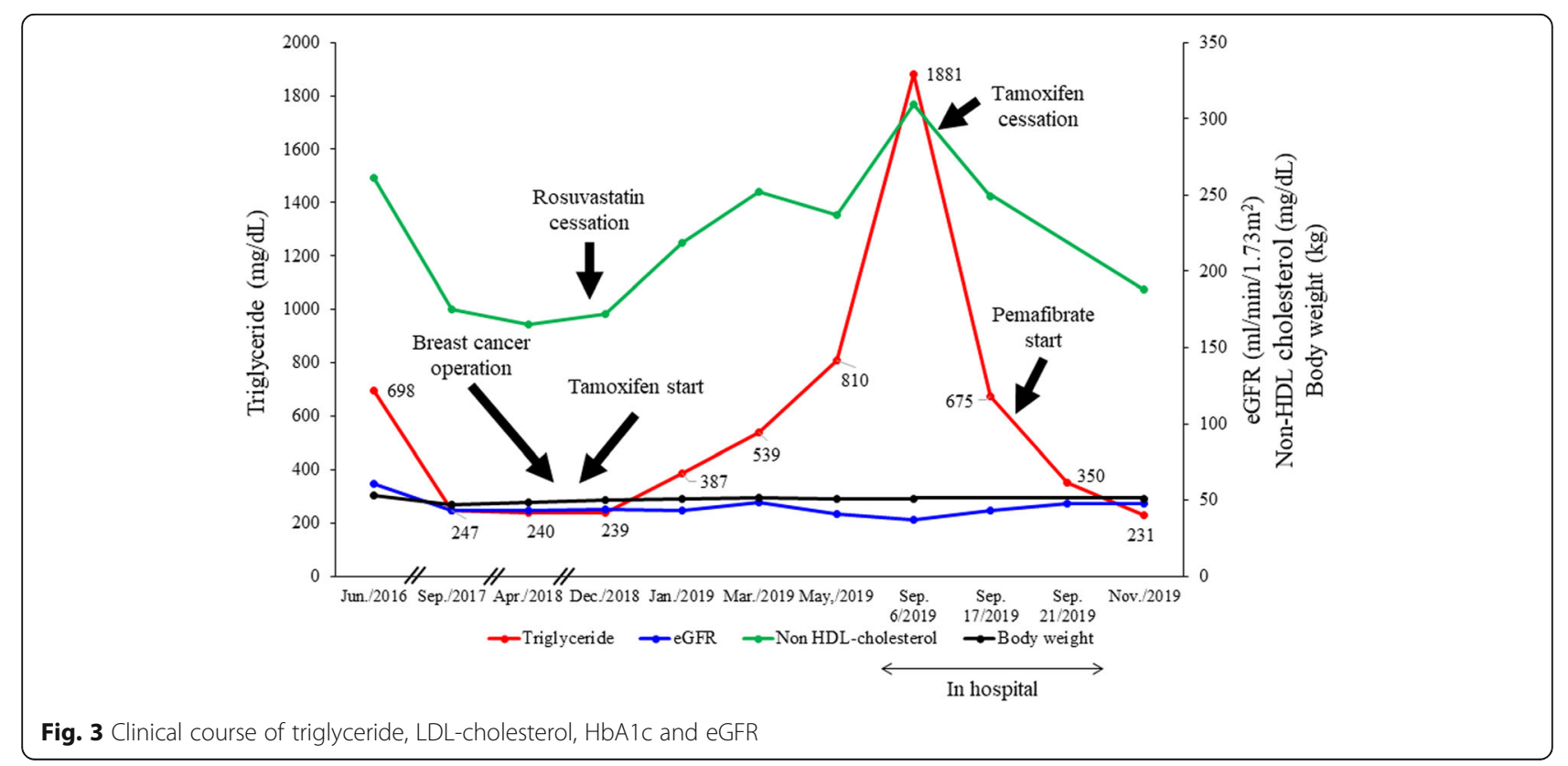


(a)

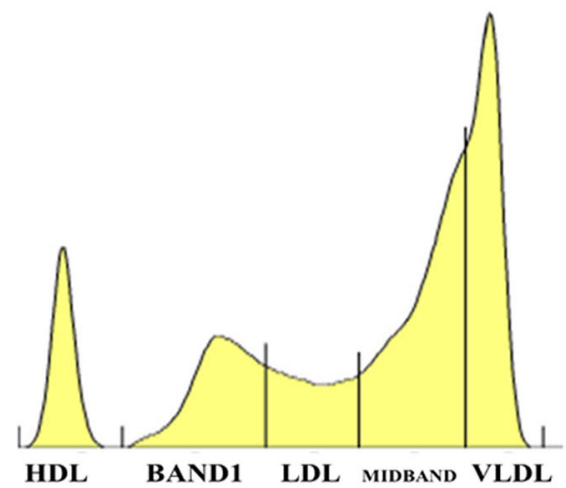

(b)

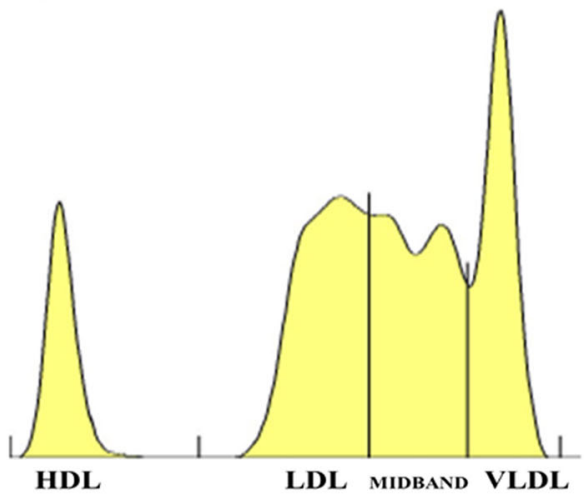

Fig. 4 Change of lipoprotein fraction test by using PAGE method after admission. (a) Seven days after tamoxifen withdrawal and (b) two months after starting pemafibrate

pancreatic necrosis, infected pancreatic necrosis, organ failure, prolonged hospitalization and death, compared to acute pancreatitis by other causes [17-19]. Therefore, it is particularly important to identify the cause in disturbance of lipid metabolism and treat hypertriglyceridemia in order to avoid the crisis of life.

Tamoxifen is one of SERMs with tissue-specific effects on estrogen signaling used predominantly for treatment and chemoprevention of breast cancers. SERMs have estrogen-like effects (agonistic action) on some tissues, but antiestrogen effects (antagonistic action) on other tissues [20]. In general, it is known that tamoxifen mainly affects lipid metabolism by its estrogenic actions, resulting in decreased LDL-C level and increased TG concentration [8-10]. Previous reports showed that estrogen impaired TG-rich lipoproteins metabolism and clearance due to suppression of post-heparin lipolytic activity [21-23]. Post-heparin lipolytic activity has been shown to consist of two activities: hepatic TG lipase (HTGL) and extrahepatic lipoprotein lipase (LPL). HTGL is the enzyme responsible for the hydrolysis of TG in different lipoproteins, contributing to the remodeling of VLDL remnants, as well as IDL, LDL and HDL. Furthermore, HTGL also acts as a ligand in accelerating the hepatic uptake of remnants and IDL particles [24]. On the other hands, LPL catalyzes the hydrolysis of TG in chylomicron and VLDL, producing chylomicron remnant and IDL, respectively. Furthermore, LPL can also act as a ligand for lipoprotein receptors to facilitate lipoprotein uptake [25]. Some groups reported that tamoxifen lowered activities of both LPL and HTGL, resulting in hypertriglyceridemia [26, 27]. The results of lipoprotein fraction test by using HPLC and PAGE methods on admission in our case also implied decreased activities of both LPL and HTGL (Fig. 1a and b). On the other hand, tamoxifen might have reduced the activity of LPL more than that of HTGL in our case, because the fractions of small dense LDL were detected clearly in the lipoprotein fraction test by PAGE method (Fig. 1b). Surprisingly, the metabolisms of endogenous lipoproteins were changed drastically 7 days after cessation of tamoxifen (Fig. 4a). Its change may imply that withdrawal of tamoxifen promptly alleviated the decrease in LPL activity. From these results, we confirmed that tamoxifen certainly changes lipoprotein metabolism through the effect on activity of LPL and HTGL.

In our case, the metabolism of TG-rich lipoproteins had already stagnated before tamoxifen administration although it is one of the causes that she could not have received the treatment with statin and/or fibrate because of renal side effect. Serum TG concentration gradually exacerbated some months after the start of adjuvant therapy for breast cancer using tamoxifen. In general, tamoxifen may need rather prolonged therapy to increase triglyceride level $[13,28]$, since short-term studies [29-31] failed to detect the changes in serum triglyceride levels. In the previous report [13], there are few cases of severe hypertriglyceridemia (TG > $1000 \mathrm{mg} / \mathrm{dl}$ ) after dosing tamoxifen. The majority of these patients had past history of hypertriglyceridemia. In addition, when family history was provided, strong family history of dyslipidemia was evident. Additionally, tamoxifen is likely to increase TG level in patients with predisposition factors that may influence susceptibility to hypertriglyceridemia including increased TG concentration before prescription, such as diabetes, obesity, chronic kidney disease (CKD), nonalcoholic fatty liver disease (NAFLD), alcohol abuse, the concomitant use of certain medications and endogenous dyslipidemia (familial hypertriglyceridemia, familial combined hyperlipidemia) [32-34]. In our case, it did not take a long time to worsen TG concentration remarkably. It may be due to overlapping of above-mentioned various risk factors, e.g. 
uncontrolled TG, diabetes, CKD, NAFLD and hereditary dyslipidemia.

Lastly, we prescribed pemafibrate which is a novel selective peroxisome proliferator-activated receptor $\alpha$ modulator (SPPARM $\alpha$ ) and has superior benefit-risk balance compared to conventional fibrates [35]. Pemafibrate resulted in further improvement in lipid metabolism as mentioned above in case presentation section.

In conclusion, we experienced a case with severe hypertriglyceridemia after administration of tamoxifen. Hypertriglyceridemia-induced acute pancreatitis might have brought out more severe clinical course. It is very important to evaluate the balance between benefit and risk before dosing tamoxifen and survey lipid profiles constantly during treatment to avoid life-threatening complication when prescription of tamoxifen is planned.

\section{Abbreviations}

LDL: Low density lipoprotein; HDL: High density lipoprotein; eGFR: Estimated glomerular filtration rate; BMI: Body mass index; үGTP: $\gamma$-glutamyl transpeptidase; ALT: Alanine aminotransferase; AST: Aspartate aminotransferase

\section{Acknowledgements}

Not applicable.

\section{Authors' contributions}

$\mathrm{HI}$ and $\mathrm{MS}$ contributed to the acquisition and interpretation of data and drafted the article. YK, FT, YK, TK, AO, KK, TM and KK contributed to the discussion. SN and HK revised the article. All authors read and approved the final manuscript.

\section{Funding}

The authors declare that there is no funding associated with this manuscript.

Availability of data and materials

Not applicable.

\section{Declarations}

\section{Ethics approval and consent to participate}

Not applicable.

\section{Consent for publication}

Written informed consent was obtained from the patient

\section{Competing interests}

HK received scholarship donation from Kowa pharmaceutical company Ltd.

\section{Author details}

${ }^{1}$ Division of Diabetes, Metabolism and Endocrinology, Kawasaki Medical School, 577 Matsushima, Kurashiki 701-0192, Japan. ${ }^{2}$ Professor with special assignment, Kawasaki Medical School, 577 Matsushima, Kurashiki 701-0192, Japan.

Received: 26 February 2021 Accepted: 1 June 2021

Published online: 09 June 2021

\section{References}

1. Heery M, Corbett P, Zelkowitz R. Precautions for patients taking tamoxifen. J Adv Pract Oncol. 2018;9(1):78-83.

2. Allred DC, Anderson SJ, Paik S, Wickerham DL, Nagtegaal ID, Swain SM, et al. Adjuvant tamoxifen reduces subsequent breast cancer in women with estrogen receptor- positive ductal carcinoma in situ: a study based on NSABP protocol B-24. J Clin Oncol. 2012;30(12):1268-73. https://doi.org/1 0.1200/JCO.2010.34.0141.
3. Jordan VC. Antiestrogenic and antitumor properties of TAM in laboratory animals. Cancer Treat Rep. 1976;60(10):1409-19.

4. Early Breast Cancer Trialists' Collaborative Group. Tamoxifen for Early Breast Cancer: An Overview of the Randomised Trials. Collaborative Group. Lancet. 1998;351:1451-67.

5. Early Breast Cancer Trialists' Collaborative Group. Effects of chemotherapy and hormonal therapy for early breast Cancer on recurrence and 15-year survival: an overview of the randomised trials. Lancet. 2005:365:1687-717.

6. Swedish Breast Cancer Cooperative Group. Randomized trial of two vs. five years of adjuvant TAM for postmenopausal early stage breast cancer. J Natl Cancer Inst. 1996;88:1543-9.

7. Braithwaite RS, Chlebowski RT, Lau J, George S, Hess R, Col NF. Meta-analysis of vascular and neoplastic events associated with tamoxifen. J Gen Intern Med. 2003;18(11):937-47. https://doi.org/10.1046/j.1525-1497.2003.20724.x.

8. Love RR, Newcomb PA, Wiebe DA, Surawicz TS, Jordan VC, Carbone PP, et al. Effects of tamoxifen therapy on lipid and lipoprotein levels in postmenopausal patients with node-negative breast cancer. J Natl Cancer Inst. 1990;82(16):1327-32. https://doi.org/10.1093/jnci/82.16.1327.

9. Bruning PF, Bonfrer JM, Hart AA, de Jong-Bakker M, Linders D, van Loon J, et al. Tamoxifen, serum lipoproteins and cardiovascular risk. Br J Cancer. 1988;58(4):497-9. https://doi.org/10.1038/bjc.1988.248.

10. Romero WG, Da Silva FB, Borgo MV, Bissoli NS, Gouvêa SA, Abreu GR. Tamoxifen alters the plasma concentration of molecules associated with cardiovascular risk in women with breast cancer undergoing chemotherapy. Oncologist. 2012;17(4): 499-507. https://doi.org/10.1634/theoncologist.2011-0369.

11. Yoneyama K, Nakagawa M. Severe acute pancreatitis due to tamoxifeninduced hypertriglyceridemia. Breast J. 2019;25(4):788-9. https://doi.org/1 $0.1111 /$ tbj.13279.

12. Mishima $Y$, Ando M, Kuyama A, Ishioka T, Kibata M. A simple method for identifying particle size of low-density lipoprotein using PAG electrophoresis: comparison between LipoPhor ${ }^{T M}$ and LipoPrint LDL $L^{\mathrm{TM}}$ systems. J Jpn Atheroscler Soc. 1997:25:67-70.

13. Elisaf MS, Nakou K, Liamis G, Pavlidis NA. Tamoxifen-induced severe hypertriglyceridemia and pancreatitis. Ann Oncol. 2000;11(8):1067-9. https:// doi.org/10.1023/A:1008309613082.

14. Fortson MR, Freedman SN, Webster PD 3rd. Clinical assessment of hyperlipidemic pancreatitis. Am J Gastroenterol. 1995;90(12):2134-9.

15. Tsuang W, Navaneethan U, Ruiz L, Palascak JB, Gelrud A. Hypertriglyceridemic pancreatitis: presentation and management. Am J Gastroenterol. 2009;104(4):984-91. https://doi.org/10.1038/ajg.2009.27.

16. Valdivielso P, Ramírez-Bueno A, Ewald N. Current knowledge of hypertriglyceridemic pancreatitis. Eur J Intern Med. 2014;25(8):689-94. https://doi.org/10.1016/j.ejim.2014.08.008.

17. He WH, Zhu Y, Zhu Y, Liu P, Zeng H, Xia L, et al. Comparison of severity and clinical outcomes between hypertriglyceridemic pancreatitis and acute pancreatitis due to other causes. Zhonghua Yi Xue Za Zhi. 2016:96(32): 2569-72. https://doi.org/10.3760/cma.j.issn.0376-2491.2016.32.011.

18. Deng LH, Xue $P$, Xia Q, Yang XN, Wan MH. Effect of admission hypertriglyceridemia on the episodes of severe acute pancreatitis. World J Gastroenterol. 2008;14(28):4558-61. https://doi.org/10.3748/wjg.14.4558.

19. Navarro S, Cubiella J, Feu F, Zambón D, Fernández-Cruz L, Ros E. Hypertriglyceridemic acute pancreatitis. Is its clinical course different from lithiasic acute pancreatitis? Med Cin (Barc). 2004;123:567-70.

20. Martinkovich S, Shah D, Planey SL, Arnott JA. Selective estrogen receptor modulators: tissue specificity and clinical utility. Clin Interv Aging. 2014;9: 1437-52. https://doi.org/10.2147/CIA.S66690.

21. Applebaum DM, Goldberg AP, Pykälistö OJ, Brunzell JD, Hazzard WR. Effect of estrogen on post-heparin lipolytic activity. Selective decline in hepatic triglyceride lipase. J Clin Invest. 1977;59(4):601-8. https://doi.org/10.1172/ JCl108677.

22. Jones DR, Schmidt RJ, Pickard RT, Foxworthy PS, Eacho PI. Estrogen receptor- mediated repression of human hepatic lipase gene transcription. J Lipid Res. 2002;43(3):383-91. https://doi.org/10.1016/S0022-2275(20)30144-9.

23. Homma H, Kurachi H, Nishio $Y$, Takeda T, Yamamoto $T$, Adachi $K$, et al. Estrogen suppresses transcription of lipoprotein lipase gene. Existence of a unique estrogen response element on the lipoprotein lipase promoter. J Biol Chem. 2000;275(15):11404-11. https://doi.org/10.1074/jbc.275.15.11404.

24. Zambon A, Bertocco S, Vitturi N, Polentarutti V, Vianello D, Crepaldi G. Relevance of hepatic lipase to the metabolism of triacylglycerol-rich lipoproteins. Biochem Soc Trans. 2003:31(5):1070-4. https://doi.org/10.1042/ bst0311070. 
25. Wang H, Eckel RH. Lipoprotein lipase: from gene to obesity. Am J Physiol Endocrinol Metab. 2009;297(2):E271-88. https://doi.org/10.1152/ajpendo. 90920.2008.

26. Brun LD, Gagné C, Rousseau C, Moorjani S, Lupien PJ. Severe lipemia induced by tamoxifen. Cancer. 1986;57(11):2123-6. https://doi.org/10.1002/1 097-0142(19860601)57:11<2123::AID-CNCR2820571106>3.0.CO;2-2.

27. Hozumi Y, Kawano M, Saito T, Miyata M. Effect of tamoxifen on serum lipid metabolism. J Clin Endocrinol Metab. 1998;83(5):1633-5. https://doi.org/1 0.1210/jcem.83.5.4753.

28. Liu CL, Yang TL. Sequential changes in serum triglyceride levels during adjuvant tamoxifen therapy in breast cancer patients and the effect of dose reduction. Breast Cancer Res Treat. 2003;79(1):11-6. https://doi.org/10.1 023/A:1023348021773.

29. Bagdade JD, Wolter J, Subbaiah PV, Ryan W. Effects of tamoxifen treatment on plasma lipids and lipoprotein lipid composition. J Clin Endocrinol Metab. 1990;70(4):1132-5. https://doi.org/10.1210/jcem-70-4-1132.

30. Engan T, Krane J, Johannessen DC, Lønning PE, Kvinnsland S. Plasma changes in breast cancer patients during endocrine therapy--lipid measurements and nuclear magnetic resonance (NMR) spectroscopy. Breast Cancer Res Treat. 1995;36(3):287-97. https://doi.org/10.1007/BF00713400

31. Gylling $H$, Pyrhönen S, Mäntylä E, Mäenpää H, Kangas L, Miettinen TA. Tamoxifen and toremifene lower serum cholesterol by inhibition of delta 8cholesterol conversion to lathosterol in women with breast cancer. J Clin Oncol. 1995;13(12):2900-5. https://doi.org/10.1200/JCO.1995.13.12.2900.

32. Mosca LJ. Therapy of hyperlipidemia. In: Crawford MH, DiMarco JP, editors. Cardiology. London: Mosby; 2000. p. 7.1-7.19.

33. Tsimihodimos V, Dounousi E, Siamopoulos KC. Dyslipidemia in chronic kidney disease: an approach to pathogenesis and treatment. Am J Nephrol. 2008;28(6):958-73. https://doi.org/10.1159/000144024.

34. Chatrath $H$, Vuppalanchi R, Chalasani N. Dyslipidemia in patients with nonalcoholic fatty liver disease. Semin Liver Dis. 2012;32(1):22-9. https://doi. org/10.1055/s-0032-1306423.

35. Yamashita S, Masuda D, Matsuzawa Y. Pemafibrate, a new selective PPARa modulator: drug concept and its clinical applications for dyslipidemia and metabolic diseases. Curr Atheroscler Rep. 2020;22(1):5. https://doi.org/10.1 007/s11883-020-0823-5.

\section{Publisher's Note}

Springer Nature remains neutral with regard to jurisdictional claims in published maps and institutional affiliations.

Ready to submit your research? Choose BMC and benefit from:

- fast, convenient online submission

- thorough peer review by experienced researchers in your field

- rapid publication on acceptance

- support for research data, including large and complex data types

- gold Open Access which fosters wider collaboration and increased citations

- maximum visibility for your research: over $100 \mathrm{M}$ website views per year

At BMC, research is always in progress.

Learn more biomedcentral.com/submissions 